\title{
Nanoeconomics: A Statistical Model of Company Profit Influenced by Individual Interests of Managers
}

\author{
Igor Sokolov $^{1}$, Anatoly Katyshev ${ }^{2}$ \\ ${ }^{1}$ Department of Physics, Tufts University, Medford, MA 02155, USA. \\ ${ }^{2}$ Martware Inc., 46 Pexton Ave, Richmond Hill, ON L4E 4Y4, Canada. \\ Correspondence: Igor Sokolov, 200 Boston Ave., suite 2600, Tufts University, Medford, MA 02155, USA.
}

Received: September 6, 2016

Accepted: September 28, 2016

Available online: October 12, 2016

doi:10.11114/aef.v4i1.1862

URL: http://dx.doi.org/10.11114/aef.v4i1.1862

\begin{abstract}
A concept and mathematical model of modern economics are formulated in which a company profit is defined when taking into account possible interests of individual decision makers rather than based exclusively on benefits of either the company (ground of microeconomics) or the whole society (ground of macroeconomics). We call this approach "nanoeconomics" as a terminological step down from macro- and micro- economics. The growing gap between interests of the business owner and decision makers in large corporations is obviously detrimental for the company performance. Here we formulate a statistical model to describe this situation quantitatively. In this model, the company profit is an accumulative effect of statistical contributions of a variety of decisions of individual decision-makers, rather than looking at the company as a whole (microeconomics). The model demonstrates the decrease of profit of the company compared to the microeconomic estimation. We study a relative contribution to the profit decrease from different human factors considered in the model, "careerism" and "expertise" of the decision-making managers, their "loyalty" to the company, and the lack of strong company management ("decentralization").
\end{abstract}

JEL: D03; B00; D21; C10; C15; C18

Keywords: economics models; decision makers; individual interests; agent-based models

\section{Introduction}

Within the frame of a modern democratic society, macroeconomics is driven by microeconomics. Microeconomic decisions are made by individuals, who are driven by both the interests of the corporation and their own personal interests. The latter part is mostly ignored when describing microeconomics. This is a subject of what we suggest to call "nanoeconomics", for short of "economics of individuals". We expect that the concept of nanoeconomics will help to better understand the driving forces for microeconomics, and eventually, the entire economics in general, to identify or at least make clear its bottlenecks and culprits.

At the time of classical capitalism, the owner and the decision maker were essentially the same person. The same situation can still be found in relatively small companies. While such examples do exist in modern economy, the mainstream of the economy is defined by large companies, corporations. In such corporations, the company interests can be relatively abstract for an individual decision-maker (if it can unambiguously be defined at all at a particular time frame). At the same time, the individual personal interests of the decision makers are typically quite clear. In everyday life, a typical decision-maker sees and reports to her/his boss and communicates with a number of subordinates. The interests of the entire company typically play a role of a sort of good abstract thing, which everybody should follow but mostly does not if it contradicts her/his own interests.

The problem described in the above paragraph is certainly well-known. It is interesting to note that this problem was described for "joint-stock" companies even by Adam Smith (Smith \& Marian S. Carson Collection (Library of Congress), 1796) back in 1796: "The directors of such [joint-stock] companies, however, being the managers rather of other people's money than of their own, it cannot well be expected, that they should watch over it with the same anxious vigilance with which the partners in a private copartnery frequently watch over their own. Like the stewards of a rich man, they are apt to consider attention to small matters as not for their master's honour, and very easily give themselves a dispensation from having it. Negligence and profusion, therefore, must always prevail, more or less, in the 
management of the affairs of such a company." Nevertheless, this problem was ignored in almost all economic theories. We conceive that it was because of several main reasons. First, the effect of "negligence and profusion" is rather hard to describe in a quantitative manner. Secondly, this problem was not a major one during the initial stages of development of capitalistic relations, when large joint-stock corporations had to compete with owner controlled businesses. Additionally, a large concentration of capital within one company gives certain advantages to such a company. This has also diminished the negative effect of "negligence and profusion". Finally, the attention of many researchers has been focused on the analysis of microeconomic effects, stock, portions, etc. markets (see, the recent review (Sornette, 2014) and references therein).

Prevailing assumptions of modern economic theories are based on ethical (Kuratko \& Goldsby, 2004) and libertarian approaches (Hargreaves, 1996; Karnani, 2010). For example, Milton Friedman claims that the sole social responsibility of business leaders is to maximize their stockholder profits (Libertarian Approach). There are those who argue that a business has ethical responsibilities to many stakeholders: employees, stockholders, retailers, customers, and so on (Dawson, 2009). Nanoeconomics is based on a different approach. In the real world, the decision maker makes a decision based neither on purely ethical responsibilities to stockholders nor on the company profit but based primarily on his/her own interests. It would be a mistake to consider such behavior of the decision-maker as unethical or unprofessional because, as we explained above own interests of the decision-maker are almost always much clearer than vaguely defined interests of the stockholders and company in general. In any case, ethical evaluation is beyond the scope of this work. It is just worth noting that historically all attempts of society to convince or force the decision makers to act against their own interests have failed.

It would be incorrect to say that economists ignore the interests of the decision-makers. Organizational conflicts and contradictions between the interests of the company and its decision-makers is a known issue in the modern economy (Riasi and Asadzadeh, 2015). The economics of discretionary behavior of managers has been analyzed for a long time (Alchian, 1965; Jensen \& Meckling, 1976; Oconnell, 1965; Ostgaard \& Birley, 1994; Ramdani \& van Witteloostuijn, 2012; Sen, 2007; Sornette, 2014; Zannetos, 1965; Zhang, Zhang, \& Chen, 2007). Agency Theory (Alchian \& Demsetz, 1972; Eisenhardt, 1985, 1989; Jensen \& Meckling, 1976), explaining conflicts of interest between corporate managers and outside equity and debt holders (shareholders). One of the interesting conclusions was that the agency problem led to an overvalued equity (Jensen, 2005). Various generalized kinetic Ising models (typicality used to explain collective behavior in physics) were developed to explain cooperative behavior of decision making (Brock \& Durlauf, 2001). In contrast to all those work, the described nanoeconomic approach is focused on the effects of individual decision making, and its contribution to the profit of a corporation described in a statistical manner. From that point of view, the majority of the models developed so far could be considered as complementary to the model formulated in this work. Specifically, the previous models have tried to describe the effect of potential conflict between corporate managers/agents and the interest of the company (shareholders) either in a qualitative manner or by using some ad hoc physical models. All that could be included in the model describing the influence of individual decision-maker on the company profit, which is the initial step of the nanoeconomic approach described in this work. To stress these differences, we will use the term "manager" for a decision maker instead of "agent" used in "agent-based" models.

The goal of the present work is to develop a numerical model describing the effect of possible contradiction between interests of the company and its decision-makers. In contrast to the existing views and theories mentioned above, we do not analyze the conditions and reasons for the said contradictions, we just assume their existence, and analyze their consequences to the company performance, profit. In addition, these contradictions are considered in a statistical (Monte-Carlo) manner, considering the entire spectrum of possible outcomes, from a full antagonist to none. Hereby we describe a mathematical ground of nanoeconomics, introduce parameters to characterize these contradictions quantitatively, and suggest quantitative statistical models for two types of businesses, retail and conveyor. The model is based on quantitative parameters that yet introduced ad hoc. We expect that these parameters can be evaluated in the future with the help of special tests, questionnaires, and analysis of the company performance.

\section{Model}

\subsection{Ground for Mathematical Formulation of Nanoeconomics}

Before we formulate a mathematical model of nanoeconomics, we need to introduce the basic assumptions which will define the ground for such a model. The basic assumption of nanoeconomics is that each decision-maker (hereafter, manager) tries to make a decision based on his or her own interest primarily rather than on the interests of the company. To demonstrate it, let us consider an example.

Example of an investment broker: an investment broker has to make a decision about an investment of $\$ 1 \mathrm{M}$. According to a typical rule, the broker gets $10 \%$ of the investment gain. At the same time, the basic compensation of the broker is independent of the investment loss. 
Let us now consider two scenarios that can be faced by the broker:

Scenario 1 . High risk/ high return. Let the probability of a $20 \%$ gain on the investment be estimated as $40 \%$ and the probability of $20 \%$ loss estimated as $50 \%$. (This formulation is certainly simplified but useful to demonstrate the idea without deviating attention to unnecessary technical details.)

Scenario 2. No risk/ low return: The probability of $2 \%$ gain on the investment is guaranteed.

One can calculate the expected gain/loss of the investor and profit of the broker. Scenario 1 result: The investor is expected to have loss of $\$ 20 \mathrm{~K}(=\$ 1 \mathrm{M} * 20 \% *(40 \%-50 \%))$; the broker is expected to gain $\$ 8 \mathrm{~K}(=\$ 1 \mathrm{M} * 20 \% * 40 \% * 10 \%)$.

Scenario 2 result: The investor is expected to have profit of $\$ 20 \mathrm{~K}(=\$ 1 \mathrm{M} * 2 \%)$; the broker is expected to gain $\$ 2 \mathrm{~K}$ $(=\$ 1 \mathrm{M} * 2 \% * 10 \%)$.

Assuming microeconomical loyalty of the broker to the investor, the broker should choose Scenario 2. Assuming prevailing nanoeconomic loyalty of the broker to his/her own interests, the broker may choose Scenario 1.

It should be noted that the word "primarily" is the key in the assumption of the manager being loyal primary to their own interest rather than the company ones. It makes the above example to be a demonstration of just one difference between micro- and nano- economical approaches. It means that there are certainly exceptions, and managers do not always behave like that. Agency theory, for example, analyzes the behavior of the agent (broker in our example) in detail, describes various factors to avoid the choice of scenario 1, and to make the agent act in the interests of the principle (investor here). Here, we do not consider these details. We just assume that Scenario 1 can be chosen. We also assume that it cannot always be done. It means that our model should take into account a variety of possible choices.

To formulate it in a rigorous mathematical way, it is instructive to consider a large number of managers within one company to average out the effect of possible exceptions. It also makes sense because nanoeconomics is to be mainly applicable to large corporations (with a large number of individual decision-makers), in which the contribution of individual decision is averaged. This leads to a conclusion that the model of nanoeconomics should be statistical, i.e., operate with probabilities.

It is also worth reminding that the above assumption about placing managers' interests above the company ones is not recognition of some sort of egoistic or amoral behavior. Most of the time, interests of large corporations are rather abstract; there is no clear connection between the corporate interests and a particular decision made by the manager. In such situation, it is rather easy for an individual to find self-justification to follow his/her interests first, which are more clearly defined for them.

A further essential simplification is that the manager's interest is directly connected to the manager's "benefits". Typically, such benefits consist of two parts:

1. Direct money-related, such as manager's income, money-related benefits, various bonuses, etc., and

2. Moral/psychological benefits, such as the respect of colleagues, managing power, corporate recognition, awards, etc.

Thus, we can formulate the basic assumptions of nanoeconomics in two assumptions defined and described below. Assumption \#1 is dealing with spending resources by managers, whereas Assumption \#2 describes resource allocation between managers.

Assumption \#1. Each business manager (decision-maker) tries to make a decision preferentially based on the desire to increase the manager's benefits (as defined above) with no direct relation to the increase of the company benefits.

At this point, we need to define the company interests/benefits. We define the company benefits as everything that leads to the increase of the company profit. (At this point, for the sake of simplicity, we do not distinguish between short-run versus long-run profits.) The example of an investment broker given above demonstrates a situation described by Assumption \#1.

Next, it is instructional to connect the manager's benefits and some measurable quantity. To do that, we formulate the following assumption \#2:

Assumption \#2. The amount of manager's benefits is mainly proportional to the value of the expenses s/he manages.

Even despite the word "mainly" used in this assumption, we realize that Assumption 2 can be far-fetched in many instances. The amount of the manager's benefits depends on many aspects of corporate life, and is defined by a variety of different factors and circumstances. Nevertheless, in the case of corporate relations, we conceive it is plausible to assume that the income and monetary related benefits are typically proportional to the amount of expenses that the manager operates. This is because the larger expenses allow the manager to supervise production of more goods/company product. As a result, the manager brings more to the company revenue, and consequently, to the company profit (though the latter may not necessarily be true if the company operates beyond the economy of scale, it is 
unlikely blamed on the manager). Hence, this manager becomes more important for the company. Furthermore, the control of larger expenses in a company correlates well with the larger power of the manager. Increasing such power can also be a strong motivation for many people.

Comparing Assumptions \#1 and 2 to the postulates of micro-and macroeconomics, one can see that individual decisions of the managers are not necessarily correlated with the company interests. While the action of Assumption \#1 typically leads to a decrease in the company profit, the result of Assumption \#2 can, in principle, be both negative and positive with respect to company profit. For example, if a manager obtains more operational expenses, it can bring more profit from the unit s/he manages if the expenses are within the economy of scale. However, since a mature company typically operates close to optimal, i.e., at the limit or beyond the economy of scale, it will then be mostly negative. We consider all possible scenarios later in this work.

One can now formulate the following conclusion:

Conclusion 1. The manager's benefits do not necessarily correlate with the company benefits.

Combining this conclusion with Assumption \#2, one can arrive at Consequence 1.

Consequence 1. Manager's decisions on the use of the managing expenses may or may not be directed towards the increase of the company benefits, i.e., profit.

The examples and conclusions described above are served to demonstrate the ideas of nanoeconomics model. The examples can be continued. The scope of the present work is to describe the basic concept of nanoeconomics and to formulate a mathematical model which would help to better understand the economics in which the interests of individual decision-makers are taken into account, and possibly to analyze non-trivial consequences for micro- and maybe macro- economics in the future.

\subsection{Formulation of the Model}

Here we propose a mathematical model to illustrate the influence of nanoeconomics postulates and assumptions on the company profit. The formulation of such model should be done to satisfy the following major requirements:

1. The model should describe the company's profit as a function of individual decision-makers, managers.

2. The model should take into account Assumptions 1,2, and should not contradict to Conclusion 1 and Consequence 1.

3. The model should be statistical; its probabilistic conclusions should not contradict to any established facts about average behavior of large companies.

While it is impossible to take into account all circumstances of individual decisions, we will assume a random nature of the correlation between those decisions and the company profit mentioned in Consequence 1. We will first introduce a model that is based on Assumption 2 and then incorporate Assumption 1 (this order is used to do a smoother mathematical formulation of the model).

Let us first introduce the known notations and concepts. The law of diminishing return states that revenue has saturation when expenses are increasing. Such relations are typically presented with an exponent function:

$$
R=R\left(-1^{-k} \bar{e}^{/ R}\right) .
$$

Here $\mathrm{R}$ is revenue, $\mathrm{E}$ is expenses, $R_{s}$ is the saturation revenue, $k$ is a scale factor.

When $k E / R_{s}<<1$, revenue is proportional to expense $\left(R=k E^{\prime}\right)$, which implies the economy of scale. In the opposite case ( $\mathrm{kE} / \mathrm{R}_{\mathrm{s}}>>1$ ),revenue is saturated at $R=R_{s}$, resulting in the diminishing return. Profit $P$ is then defined as follows

$$
P=R-E={ }_{s} R\left(f^{-k E} e^{s}\right) \quad-.
$$

Maximizing profit with respect to expense, we can find that the maximum profit is reached at $\mathrm{E}_{\max }=$ 燫 $\times \log (\mathrm{k}) / \mathrm{k}$. One can now rewrite eq.(1) as

$$
\mathrm{R}=\frac{\mathrm{k} \times \mathrm{E}_{\max }}{\log (k)}\left(1-\mathrm{k}^{-\mathrm{E}^{-E_{\max }}}\right)
$$

One can relate the scale factor $\mathrm{k}$ to the return on investment (ROI) defined as

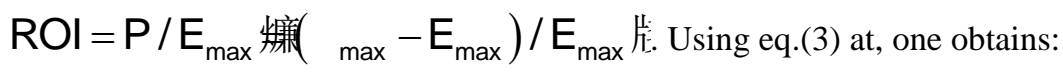




$$
R O E[k 1-L q g) A / L c .
$$

For example, if $R O I=1.5$, it corresponds to $k \approx 5$. For definiteness, hereafter, we will use $k=5$.

Figure 1 shows the revenue and profit versus expense curve described by eqs.(1-3). One sees a classical behavior of the profit versus expenses. To make the presentation independent of absolute monetary values, we plot both revenue and profit relative to $\mathrm{E}_{\max }$. Let us now consider a company with $N$ managers. The revenue produced by an individual manager $i \quad(i=1, . ., N), \mathrm{R}_{\text {manager }}(i)$ can be defined as follows:

$$
\mathrm{R}_{\text {manager }}(i)=k \frac{\mathrm{E}_{\max }(i)}{\log (k)}\left[1-k^{-E(i) / E_{\text {max }}(i)}\right]
$$

where $E(i)$ is the expense that $i$-manager operates, $E_{\max }(i)$ is the expense corresponding to the maximum profit produced by $i$-manager.
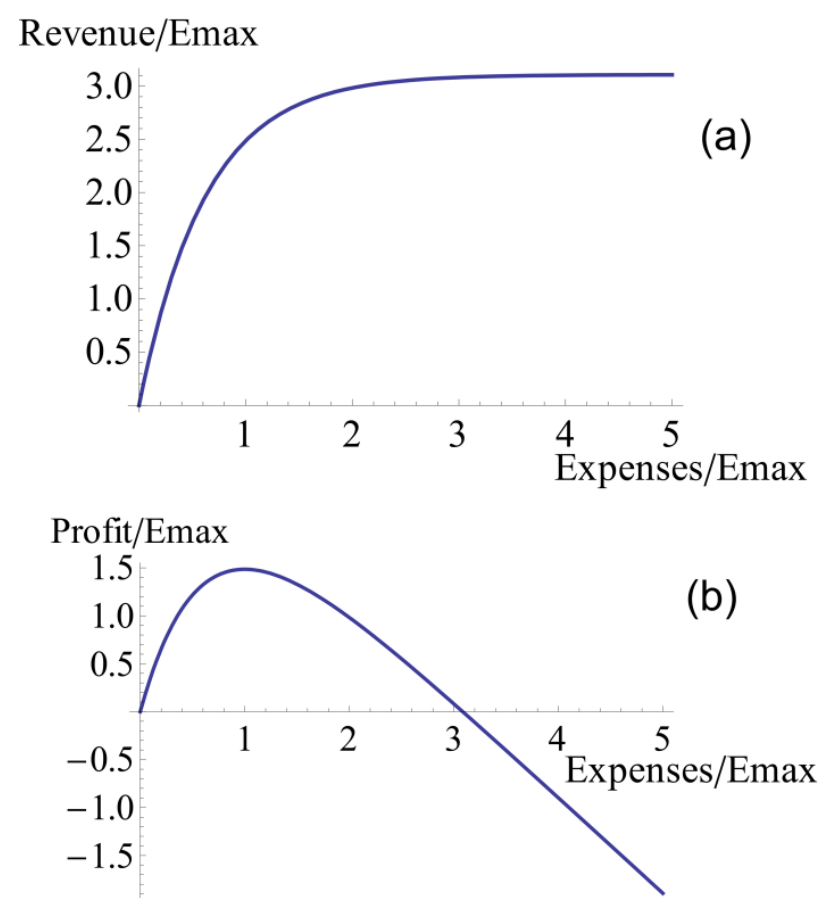

Figure 1. Revenue and profit versus expenses curve described by eq.(1). The values given are relative to $E_{\max }$.

\subsubsection{Incorporation of Assumption 2}

First, we introduce the profit versus expense dependence for two different types of business, retail- and conveyer- types. To demonstrate the effect of nanoeconomics in these models, we remove the excessive complexity by assuming the $E_{\max }(i)=E_{\max }$ for all $\mathrm{N}$ managers $(\mathrm{i}=1 . . \mathrm{N})$ of the company.

The effect from individual decisions of manages can be rather different in various types of business. For example, if we consider retail-type of business, the effect/profit coming from different managers is additive. Work of one manager is almost independent of the work of the others. However, if we consider a conveyer-type business, a problem of one manager can slow down the entire process. In this case, the effect will be multiplicative. In principle, one could consider a complex model which unifies both these types of business. However, we will consider only these two types separately for the sake of simplicity.

Model of "retail" business . Here we calculate the revenue of a company as a sum of revenue coming from individual managers as follows

$$
\mathrm{R}=\frac{k \mathrm{E}_{\max }}{\log (k)} \sum_{i=1}^{N}\left[1-k^{-E(\mathrm{i}) / \mathrm{E}_{\max }}\right] .
$$

Model of "conveyer" business. Since the company revenue in such type of business is defined by a chain of actions 
of multiple managers, the revenue should be defined as a multiplication of weighted revenues given by eq. (3):

$$
\mathrm{R}=N \frac{k \mathrm{E}_{\max }}{\log (k)} \prod_{i=1}^{N}\left[1-k^{-E(\mathrm{i}) / \mathrm{E}_{\max }}\right]^{1 / N} .
$$

This equation becomes obvious if one uses the analogy with the probability theory. When an event requires a series of sub-events to happen, the probability of the event is given by the multiplication of probabilities of the sub-events. In principle, a company can have both types of business within one structure. Then, the revenue will be described by a combination of equations (6) and (7). For the sake of simplicity, we will not consider such cases in the present work.

The company profit is given by eq.(2). Obviously, if all managers receive expenses $E(i)=E_{\max }(i)$, the company profit will be maximized. However, according to our assumption 2, each manager tries to increase her/his (operational) expense. This should create a distribution of expenses $E(\mathrm{i})$. Broadness of such distribution (standard deviation) should be defined by the style of the senior manager who defines the expenses for each manager. It can be called "decentralization". For example, a large decentralization of such distribution may indicate a weak senior management who could not resist the requests of the most active managers. This creates a broader distribution of the managers' expenses $E(i)$. The deviation or bias from the average expense of individual manager can be called "careerism". For example, a large "careerism" implies an active manager who is hungry to advance his/her career, who keeps requiring more resources/expenses.

The distribution of expenses $E$ (i) can be modeled, for example, either by the normal or uniform distributions (as will be shown below, the results are qualitatively the same with both distributions). In the case of normal distribution, probability density $p(i)$ that $i$-manager receives expense $E(\mathrm{i})$ is given by

$$
p(i)=\exp \left[-(E(i)-\bar{E})^{2} /\left(2 \sigma^{2}\right)\right] / \sqrt{2 \pi},
$$

where $\bar{E}$ is the average expense in the company per manager, $\sigma$ is the standard deviation of the distribution.

Careerism $C$ and decentralization $D$ can now be defined as

$$
\bar{E}=E_{\mathrm{m} a}\left(1+C, \quad \sigma=D^{*} \bar{E} .\right.
$$

In these definitions, both careerism and decentralization are dimensionless and independent of a particular value of the expenses. Note that the introduced careerism and decentralization are parameters integral for the whole company.

In the case of uniform distribution, the probability is constant for a possible range of expenses $E(i)$ on a given interval of allowable $E(i)$.To make it quantitatively aligned with the parameters of normal distribution, we will consider the interval of $\bar{E}-\sqrt{3} \sigma<E(i)<\bar{E}+\sqrt{3} \sigma$. (Note that $\sqrt{3}$ is added to make the definition of standard deviation quantitatively comparable to the one for the normal distribution.) Lastly, to avoid artifacts of zero or negative expenses, which can happen for a large decentralization, we restrict the minimum expense by $\bar{E} / 100$.

\subsubsection{Incorporation of Assumption 1}

We now further extend the model described above by introducing additional factors of possible actions of the managers, which can further decrease profit, Assumption 1. We speak about, either a conscious choice of the manager's own interests that can harm the company profit (lack of loyalty to the company), or uneducated decisions that can lead to the same effect, the decrease of profit (lack of expertise). Because of the conscious choice, we assume that loyalty results in a statistical non-zero bias decreasing the profit. At the same time, the lack of sufficient expertise works as a dispersion (standard deviation) smearing the biased profit decrease (both in positive and negative direction).

Similar to the previous case, we introduce action of the above factors in a statistical manner. We introduce a stochastic dimensionless quantity $\theta(i)$, which represents a decrease of profit of individual manager $i$ to the lack of loyalty and expertise. The formulas for revenue of retail-type of business will be modified as follows

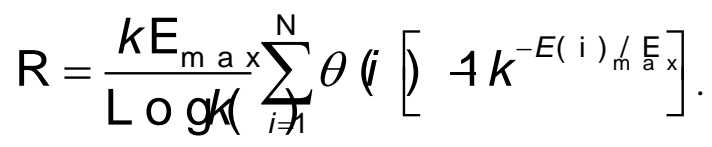

The same modification for the conveyer-type of business is given by 


$$
\mathrm{R}=N \frac{k \mathrm{E}_{\max }}{\log (k)} \prod_{i=1}^{N}\left[\theta(i)\left(1-k^{-E(\mathrm{i}) / \mathrm{E}_{\max }}\right)\right]^{1 / N} .
$$

To avoid unlikely negative revenue and the increase of the revenue above its theoretical (optimal) level, which both can happen for a large standard deviation, we restrict $\theta(i)$ to $0<\theta(i)<1$ (though a slight extension of this interval does not change the conclusions of this work). Let $\theta(i)$ be described by a part of the normal distribution (within the limits $0<\theta(i)<1)$ :

$$
\exp \left[-(\vartheta(i)-L)^{2} /\left(2 \sigma^{2}\right)\right] / A,
$$

where $A$ is normalization constant, $L$ is "loyalty" (to the company) bias, standard deviation $\sigma$ relates to "expertise" EXr as follows $\sigma=1-E X r$. Let both $L$ and Exr range between 0 and 1 (or $0-100 \%$ ). For example, $0 \%$ loyalty with $100 \%$ expertise will zero the company revenue. $100 \%$ loyalty and $100 \%$ expertise will eliminate the effect of Assumption 1, and eq.(10) and (11) will turn into eq. (6) and (7). It is worth noting that there is no need to consider the uniform distribution separately with this definition (it can effectively be obtained for rather large $\sigma$; although $\sigma$ in our model is not greater than one, this limit can be considered as sufficiently close to the uniform distribution -- it deviates only $10 \%$ in the probability density for the entire interval, for example, if $\mathrm{L}=0.5$ ).

\section{Results and Discussion}

\subsection{Simple Demonstration of the Model}

Before demonstrating the full statistical power of the described model, we describe how it works using the example of just one decision-maker/manager. Let the maximum profit be 1.5 times the ideal maximum expenses (ROI=1.5 or k=5, is chosen, see eq.(4)). Thus, the maximum profit is equal to 150 times $E_{\max }$ ( $E_{\max }$ is the expense corresponding to the maximum profit). For definity, let us consider $E_{\max }=\$ 1 \mathrm{M}$. The decrease of the company profit can come on both stages: money allocation (assumption 2) and spending (assumption 1). Let us demonstrate how this happens.

Money allocation: potential inefficiency and losses at the step of money allocation are described in our model with the help of two parameters, careerism and decentralization.

Careerism means that the manager always tries to allocate more budget that might be needed. As a result, the profit always moves to the right on the profit curve exemplified in Figure 1b. If the expenses the manager receives are still less than $\$ 1 \mathrm{M}\left(E_{\max }\right)$, the effect of careerism can be positive, it brings more profit to the company. If the manager's efforts result in receiving expenses higher than $\$ 1 \mathrm{M}$, careerism results in the profit decrease. Obviously, it is oversimplified situation which has only one aim, to demonstrate the meaning of definitions of the parameters introduced in the nanoeconomics model. In reality, companies have limited budget, which implies that the increase of operational budget for one manager leads to its decrease for the other one. This will be considered later in our analysis of the full-scale statistical model.

Decentralization. Allocation of resources cannot only be biased due to the careerism as described above, it can also be statistically distributed. For example, it can be normally distributed. Let us say that the manager asked for $\$ 1.5 \mathrm{M}$ for expenses. Depending on the style of the senior manager responsible for the budget location, such a high request might be out of consideration (strong senior management), or might be possible if the asking manager is sufficiently persistent (weak senior management). We characterize this strength of the senior management by the parameter called decentralization. The larger decentralization, the higher probability for the persistent manager to receive the requested $\$ 1.5 \mathrm{M}$. In contrast to the effect of careerism, there is no simple method to define what happens to the profit-expense curve of Figure 1b when we take into consideration decentralization. As we will demonstrate later, nonzero decentralization change the shape the profit-expense curve by always decreasing the profit for each specific expense.

Money spending: potential inefficiency and losses at the step of money spending are described in our model with the parameters of loyalty and expertise.

Loyalty. Higher loyalty means that the devotion of the managers to interests of the company. As a rather simple example, $80 \%$ of loyalty implies that $80 \%$ of all decisions made by the manager will be made based on the sole interests of the company. It means that if such manager received $\$ 1 \mathrm{M}$ for expenses, her performance would bring to the company only $\$ 1.2 \mathrm{M}$ revenue ( $80 \%$ of the maximum revenue of $\$ 1.5 \mathrm{M}$ ). In general, non-100\% loyalty always leads to the decrease of the company profit.

Expertise. To guarantee some performance, the managers must have a strong expertise. In reality managers can have the expertise less than desired/needed. It means that the expenses are not necessarily spent the most effective way. However, some uneducated manager's decisions do not always work towards decreasing the company profit. Therefore, the 
expertise relates to the dispersion (standard deviation) of the revenue brought by such a manager. Because each manager can be biased by her loyalty, the statistical effect of expertise is biased by loyalty. $100 \%$ expertise means zero standard deviation; all managers are knowing perfectly what they are doing. The decrease of profit in such a case is dictated only by loyalty. As we mentioned, $0 \%$ loyalty with $100 \%$ expertise will zero the company revenue. $100 \%$ loyalty and $100 \%$ expertise will eliminate the nanoeconomy effect of these parameters. In general, the effect of the expertise parameter less than $100 \%$ can be quite complicated. For a reasonable loyalty, it will always lead to the decrease of the company profit. However, if the loyalty is really bad, the lack of expertise may really bring more profit to the company (see, Figure 10a and the discussion around it). An example of such a paradoxical result can probably be found in the ancient enterprises which rely on the labor of slaves. When slaves were not loyal, uneducated slaves had less knowledge not only how to do work, but also how not to do it properly. As a result, such company worked with rather small profit (though not requiring loyalty). It is interesting to note that this effect exists in rather simple "retail" type of business, and is not observed in the more organized "conveyer" type of business, see the descriptions below.

\subsection{Full-scale Statistical Model}

Hereafter we will analyze profit of a company with 100 managers, whose operational expenses are randomly distributed about a given value defined by their careerism and the company decentralization. We consider both normal and uniform distributions of the expenses. 20-50 random realizations are used to demonstrate the statistical variation of profit for each given condition. We will start from the model based on Assumption 2 (eqs. (6,7)), then consider the influence of Assumption 1, and finally analyze a general case when both Assumptions 1 and 2 (eqs. $(10,11)$ ) are taken into account. We also consider both cases of a retail- and conveyer- type of business.

\subsubsection{Results for Models Based on Assumption 2}

Figure 2a demonstrates the result of the careerism $C$ in the case of a retail-type business. The bigger careerism, the more expense is requested/received by each manager. The ideal expense (careerism $=$ decentralization $=0$ ) corresponds to the number of managers (100) multiplied by $E_{\max }$; the maximum profit is 1.5 times the ideal maximum expenses (ROI=1.5 or $\mathrm{k}=5$, is chosen, see the Model section) gives 150 times $E_{\max }$.

To stress the result of the careerism, we choose a simple case of no randomization (decentralization $D=0$; no statistical variations of the expenses per individual manager). As previously, profit and expenses are normalized per the expense corresponding to the maximum profit per one manager, $E_{\max }$. A solid curve of Figure 2a stands for $C=0 \%$. It shows the profit for expenses starting from zero and up to the maximum a value when the profit becomes zero. If careerism becomes $100 \%$ (while decentralization is still 0), the profit curve just extends towards $100 \%$ higher expenses. One can observe substantial losses for those expenses. It should be noted that careerism of $100 \%$ is not the maximum, but just the shift of the average expense in the company per manager by a factor of 2 , eq. (9). Higher values can definitely be considered as well.

Figure $2 \mathrm{~b}$ shows the same case of careerism $C=0$ and $100 \%$ but for non-zero decentralization of $D=50 \%$. Here we consider the case of normal distribution, eq. (8). The "solid" part of the curve (careerism $=0$ ) is now a bit washed out due to decentralization (multiple statistical realizations of different expense distributions between managers are generated). One can see that instead of a line, one has a cloud of points. It is important to note that the profit decreases on average due to the decentralization.

It is interesting to note an effective strategy: if resources are limited, the total expenses could be "renormalized" back to the old value by a proportional decrease of the expenses of all managers. This results in complete recovery of the profit-expense curve back to careerism $=0$ case. While being rather trivial when decentralization $\mathrm{D}=0 \%$, this conclusion does not seem to be obvious in the case of non-zero decentralization (when managers get different amounts). The rich managers are still richer after such renormalization, but only relative to the other managers within the same company. However, the total expenses will remain the same. This result holds for both retail and conveyer types of company, different statistical distributions, and even when Assumption 1 is taken into account. To conclude the role of careerism, non-zero careerism does not change the shape of profit-expense curves, it just moves the expenses towards larger values (this effect can even disappear for the case of normalization described above). That is why we do not consider different careerism in profit-expense curves plotted later in this work. 

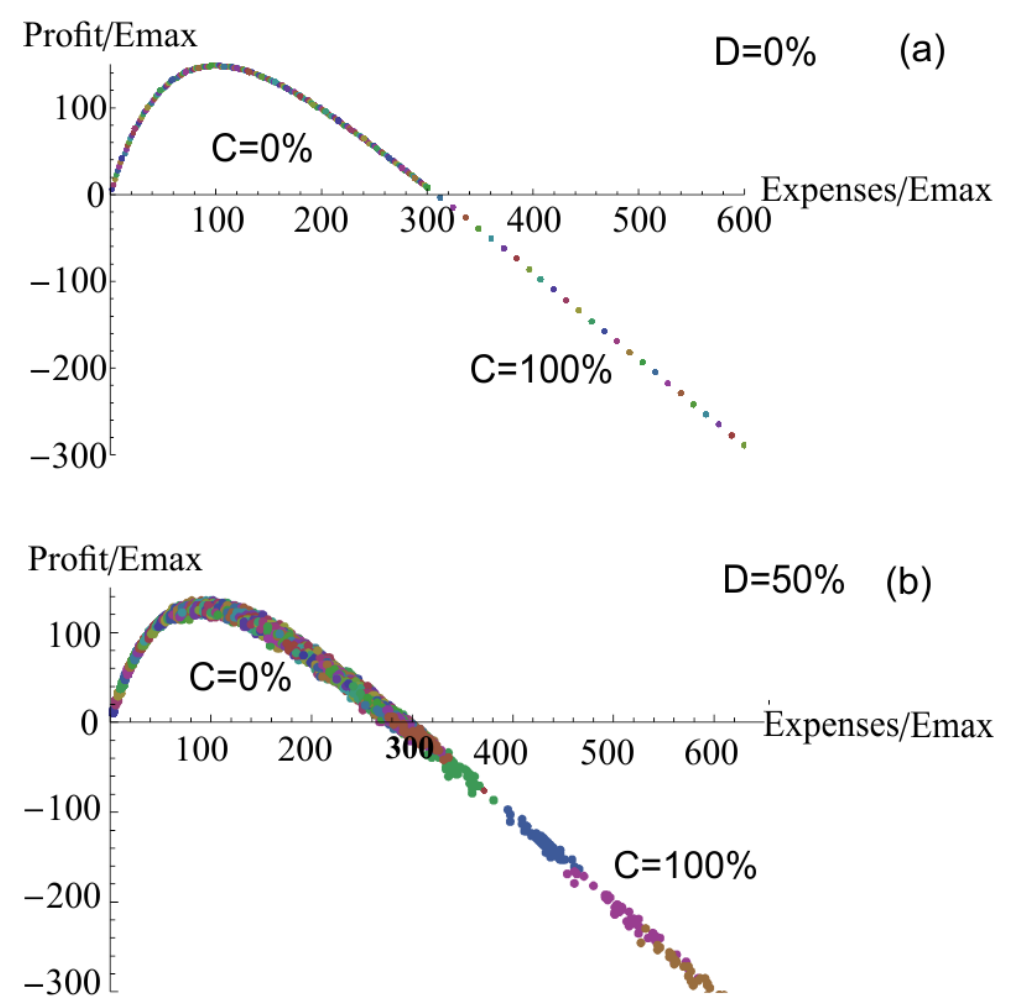

Figure 2. Retail-type Business. Effect of Careerism $(C)$ and Decentralization $(D)$ on the Company Profit. The Cases of $\mathrm{C}=0$ and $100 \%$ are shown When (a) $\mathrm{D}=0$ and (b) $50 \%$.

Comparing Figs.2a and b, one can see that the profit decreases per each averaged expense when decentralization is not zero. This nontrivial result of decentralization is magnified in Figure 3 by presenting the results for decentralization $=0$, 50, and $100 \%$. The expenses in Figure 3 are limited by the ratio Expenses/Emax 300, which corresponds to approximately zero profit in the case of careerism $=$ decentralization $=0$. This figure shows the results of simulation of expenses distributed (a) normally and (b) uniformly. For the case of uniform distribution, the largest decentralization considered is $75 \%$. This was taken to make the profit-expense curves similar to the normal distribution when $D=100 \%$. This implies that negative effect of decentralization seems to be stronger in the case of uniform distribution.

One can clearly see from Figure 3 that the presence of decentralization leads to the decreased values of profit for a given expense. The profit maxima are now smaller and reached for smaller expenses compared to the ideal maxima. This is observed for both normal and uniform distributions (while being more pronounced for the case of normal distribution). 

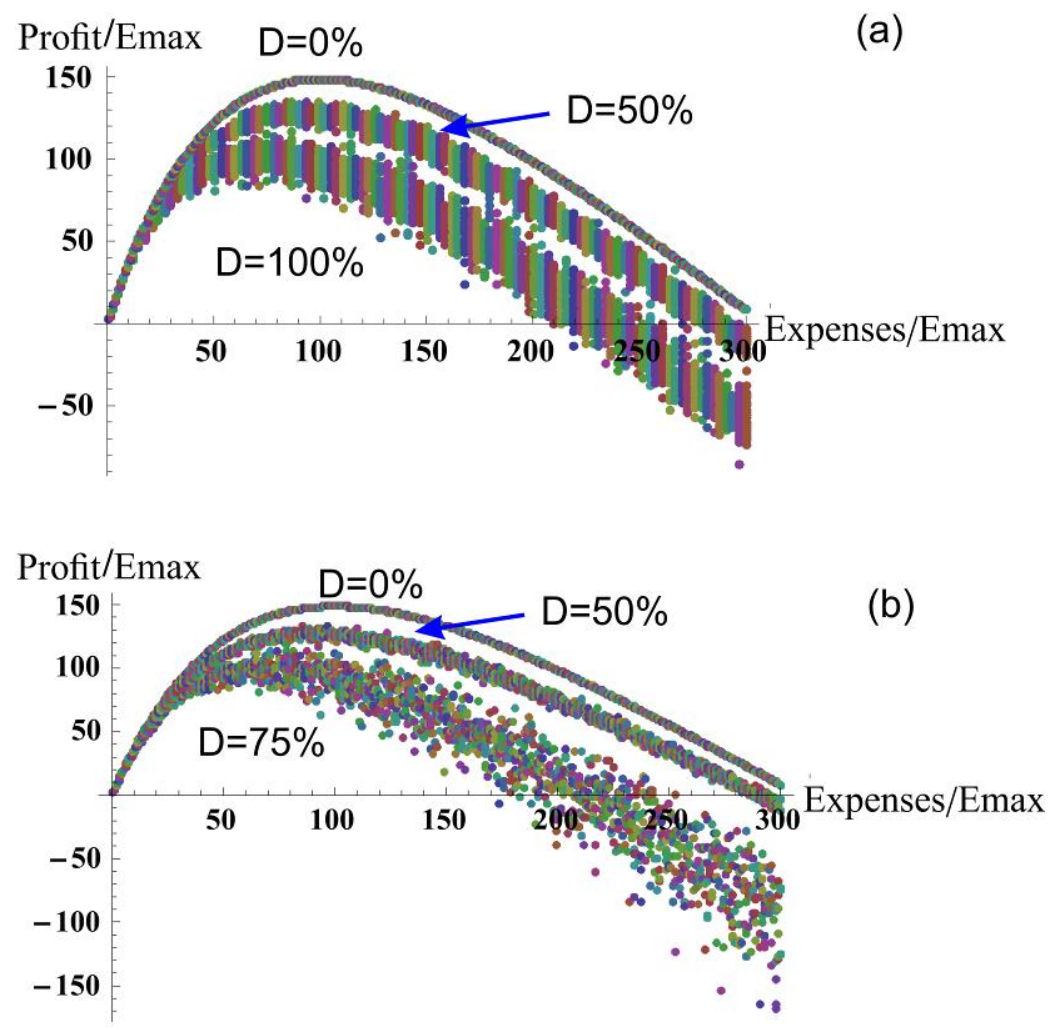

Figure 3. Retail-type business. Effect of decentralization $(D)$ a) Normal distribution of expenses among managers with $D=0,50$ and $100 \%$, (b) Uniform distribution of expenses among managers with $D=0,50$ and $75 \%$. Careerism does not change the shapes of the curves.

Figure 4 shows the results of simulations similar to the shown in Fig,3 but now for a conveyer-type company. The same parameters are used as previously in the case of retail company, 100 managers, 30 random realizations of statistically distributed expenses for the case of normal $(D=0,50$ and 100\%) and uniform $(D=0,50$ and $75 \%)$ distributions are shown for the dispersions (standard deviation) in Figs. $4 \mathrm{a}$ and b, respectively. One can see that the results of decentralization of distribution of the manager expenses are much stronger compared to the retail company. This is not a surprised because weak work of a few individual managers hits the performance of the entire company. The case of $75 \%$ decentralization in the case of the uniform distribution shows virtually no positive profit. 
Profit/Emax

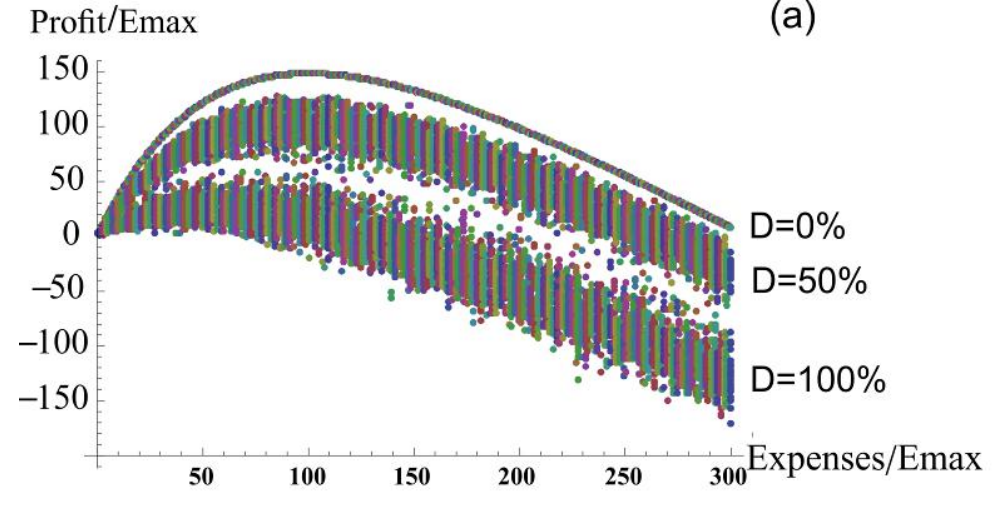

Profit/Emax

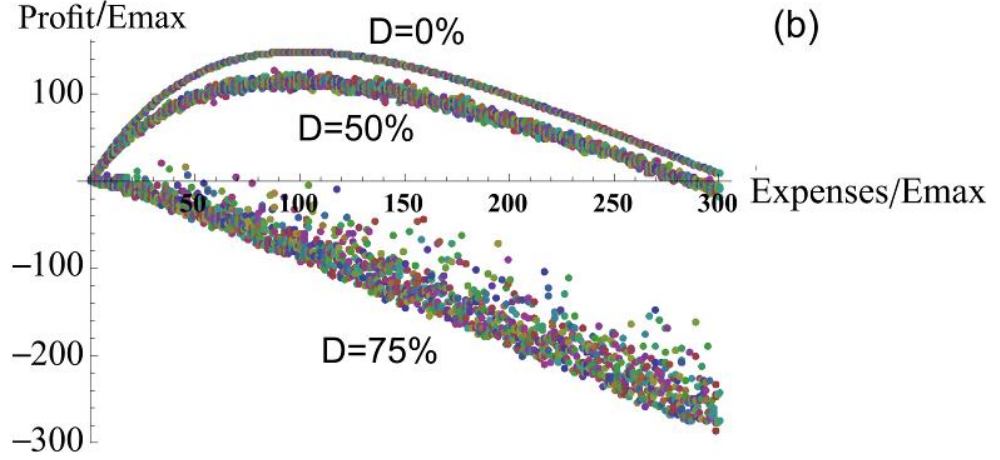

(a)

Vol. 4, No. $1 ; 2017$

Figure 4. Conveyer-type business. Effect of decentralization $(D)$ a) Normal distribution of expenses among managers with $D=0,50$ and $100 \%$, (b) Uniform distribution of expenses among managers with $D=0,50$ and $75 \%$. Careerism does not change the shapes of the curves.

It is interesting to analyze the obtained results. Large careerism indicates an excessively strong motivation of the managers towards their careers. A large decentralization can be a result of weak senior management. The results of the simulations above demonstrate that the higher profit can be achieved when the resources are limited (within the economy of scale), and the senior management is strong (preventing large dispersion/ standard deviation). The latter plays more negative role than careerism, in particular, within the economy of scale. It is particularly paramount for the case of conveyer-type company.

\subsubsection{Results for Model Based on Assumptions 1}

Let us now consider the effect of additional factors of possible actions of the managers, which were described by loyalty and expertise introduced via Assumption 1. To demonstrate the effect of just Assumption 1, we use eqs. $(10,11)$ with careerism $(C)$ and decentralization $(D)$ both equal to zero (this eliminates the effect of Assumption 2). As previously, we consider two types of business, retail and conveyer.

Retail type of business: Figure 5 shows the effect of loyalty $L$ and expertise $E x r$ on the profit-expense dependence for a retailer-type of business. In the case of $L=E x r=100 \%$, one has the ideal curve of microeconomics. Figure $5 \mathrm{a}$ demonstrates cases of changing only loyalty L, from $100 \%$ to $0 \%$ while keeping expertise $E x r=100 \%$. Figure $5 \mathrm{~b}$ shows the cases of changing only expertise Exr, from $100 \%$ to $0 \%$ while $L=100 \%$. Finally, Figure $5 \mathrm{c}$ presents the effect of combined non-ideal loyalty and expertise. 


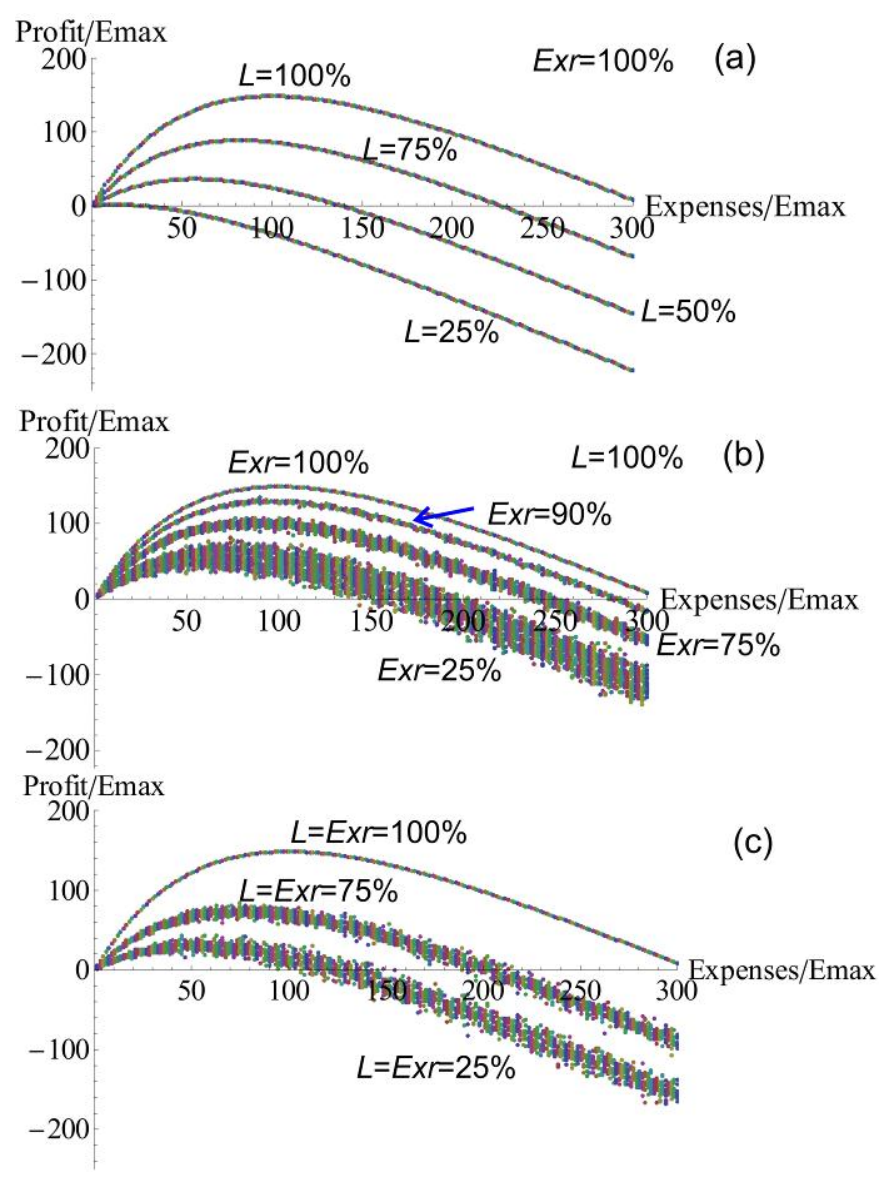

Figure 5. Retail-type business. (a) Loyalty $L=100,75,50,25 \%$. Expertise $E x r=100 \%$. (b) Expertise $E x r=100 \%$. 90, 75, $25 \%$. Loyalty $L=100 \%$. (c) A combined effect: $L=E x r=100,75$, and $25 \%$.

One can see from Figure 5a that the effect of loyalty is rather strong. The profit drops rather substantially with a decrease of loyalty of managers to the company. It is interesting to note that if the amount of managers loyal to the company is only $25 \%(L=25 \%)$, the company cannot produce any profit at any expense. If $L=50 \%$, the company can reach the maximum profit of $120 \mathrm{E}_{\max }\left(80 \%\right.$ of the ideal $\left.150 \mathrm{E}_{\max }\right)$.

Figure $5 b$ shows that the lack of expertise of managers is equally diminishing for the company profit. However, it is not as strong as the lack of loyalty for smaller $E x r$ and $L$. Figure 5c demonstrates that the effect of both non-ideal Exr and $L$ is complicated. It can be accumulative, contributing to the profit decrease, when Exr and $L$ start to deviate from $100 \%$. However, in the case of Exr and $L=25 \%$, low expertise helps to improve profit (it is no longer zero as in Figure 5a). This is obviously the effect of washing out the non-loyal action of managers. Simply speaking, disloyal managers with low expertise cannot make even a "good" disloyal decision. This situation is analyzed in more details and presented in Figure 6. 

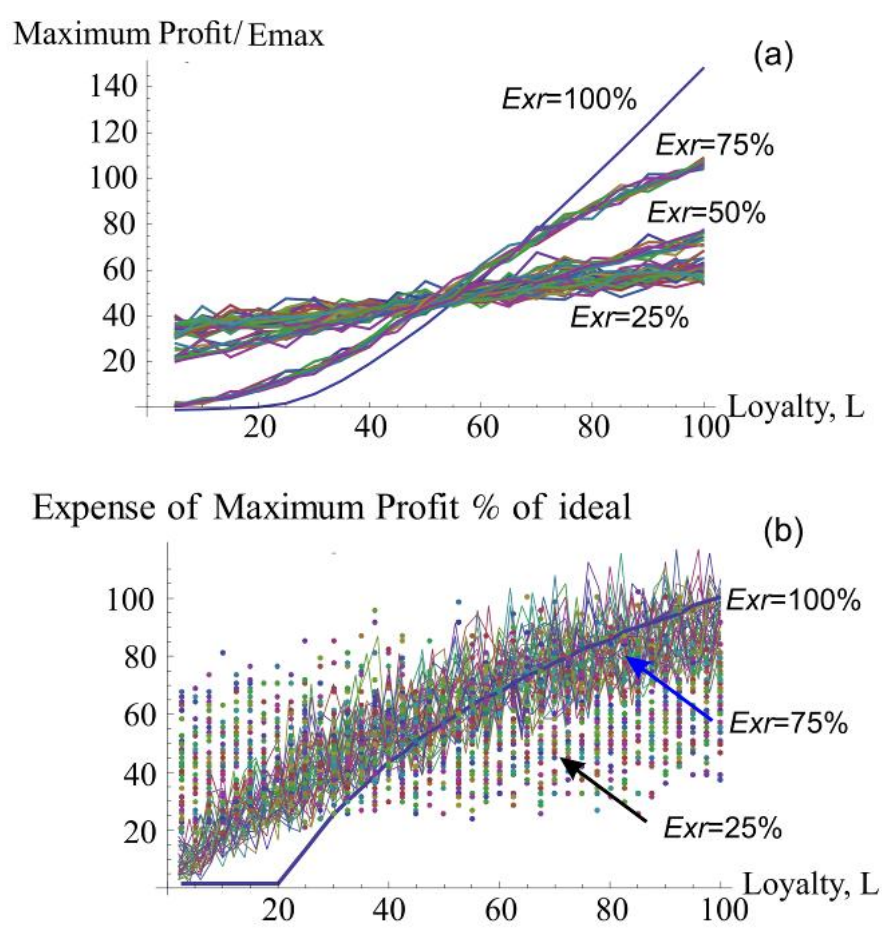

Figure 6. Retail-type business. (a) The maximum profit found from the profit-expense curves for loyalty ranging from $0-100 \%$ and $E x r$ taken at ( $E x r=100 \%, 75,50,25 \%$ ). Ideal maximum profit is $150 / \mathrm{E}_{\max }$. (b) The expense corresponding

to the maximum profit found from the profit-expense curves for a range Loyalty $L$ of $0-100 \%$ and $E x r$ taken at

(Exr $=100 \%, 75,25 \%)$. Ideal maximum profit is $150 / \mathrm{E}_{\max }$. The expense corresponding to the max profit is $100 / \mathrm{E}_{\max }$.

Figure 6a shows the maximum profit found from the profit-expense curves for multiple loyalty $L$ values ranging from $0-100 \%$ and expertise $E x r$ (taken at $100 \%, 75,50,25 \%)$. One can see that the effect of expertise $(E<50 \%)$ is inversed at loyalty $L \sim 50-70 \%$. Figure $6 \mathrm{~b}$ shows the results of the analysis of expenses that correspond to the maximum profit. These expenses depend on both loyalty (generally decreasing with the decrease of loyalty) and experience (decreasing (for $\mathrm{L}>50 \%$ ) and increasing (for $\mathrm{L}<40 \%$ ) with the decrease of experience). It is important to note that in all cases, the expense of maximum profit is always smaller than the expense corresponding to the ideal profit. This leads to an interesting conclusion that if a company is losing profit due to nanoeconomical factors, to reach the maximum profit, one needs to decrease the expenses compared to the microeconomical estimations. This result stays almost unchanged when we consider a combination of the other nanoeconomical factors (due to Assumption 2), see below.

Conveyer type of business: Here we describe the analysis similar to the one presented above (Figs. 5,6). As previously, the case of $L=E x r=100 \%$ gives the ideal curve of microeconomics. In the case of Exr=100\%, there is no statistical variability, and $\theta(i)$ is the effectively the same for all managers. Thus, the factor $\theta(i)$ can be extracted from the multiplicative part of eq.(11) in the same way as in eq.(10). Therefore, there should be no difference between retail and conveyer types of businesses in the diminishing effect of loyalty in this case. In the case of non-ideal Exr, the difference is clearly visible. Figure 7a shows the effect of changing expertise Exr, from $100 \%$ to $0 \%$ while keeping loyalty $L=100 \%$. Finally, Figure $7 \mathrm{~b}$ presents the effect of combined non-100\% loyalty and expertise. 


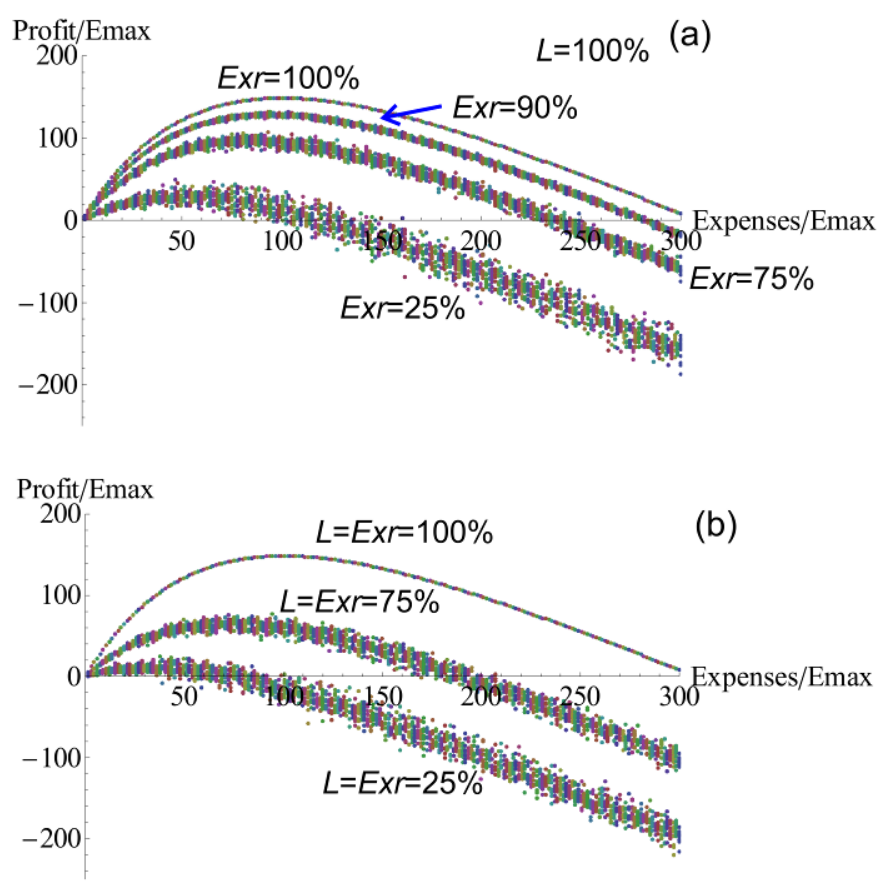

Figure 7. Conveyer-type business. (a) Expertise $E x r=100 \%, 90,75,25 \%$. Loyalty $L=100 \%$. (b) A combined effect: $L=$ $E x r=100,75$, and 25\%. The case of zero expertise is equivalent to the retail-type of business.

One can see from Figure 7a that a non-ideal Exr gives almost the same effect as for the retail type of business, except small expertise. In the latter case, the drop of profit is now stronger (compare with Figure $5 \mathrm{~b}$, Exr=25\%). The same trend we see in Figure $7 \mathrm{~b}$ (compared with Figure 5c). The combined effect of both non-100\% loyalty and expertise gives almost the same result as for the retail type of business except the small expertise $L=E x r=25 \%$, where the profit for conveyer type of business again suffers stronger than the profit of retail-type. Similar to the retail type of business, one can observe that low expertise helps to improve profit (it is no longer zero as in Figure 5a) in the case of $L=E x r=$ $25 \%$ shown in Figure $7 \mathrm{~b}$.
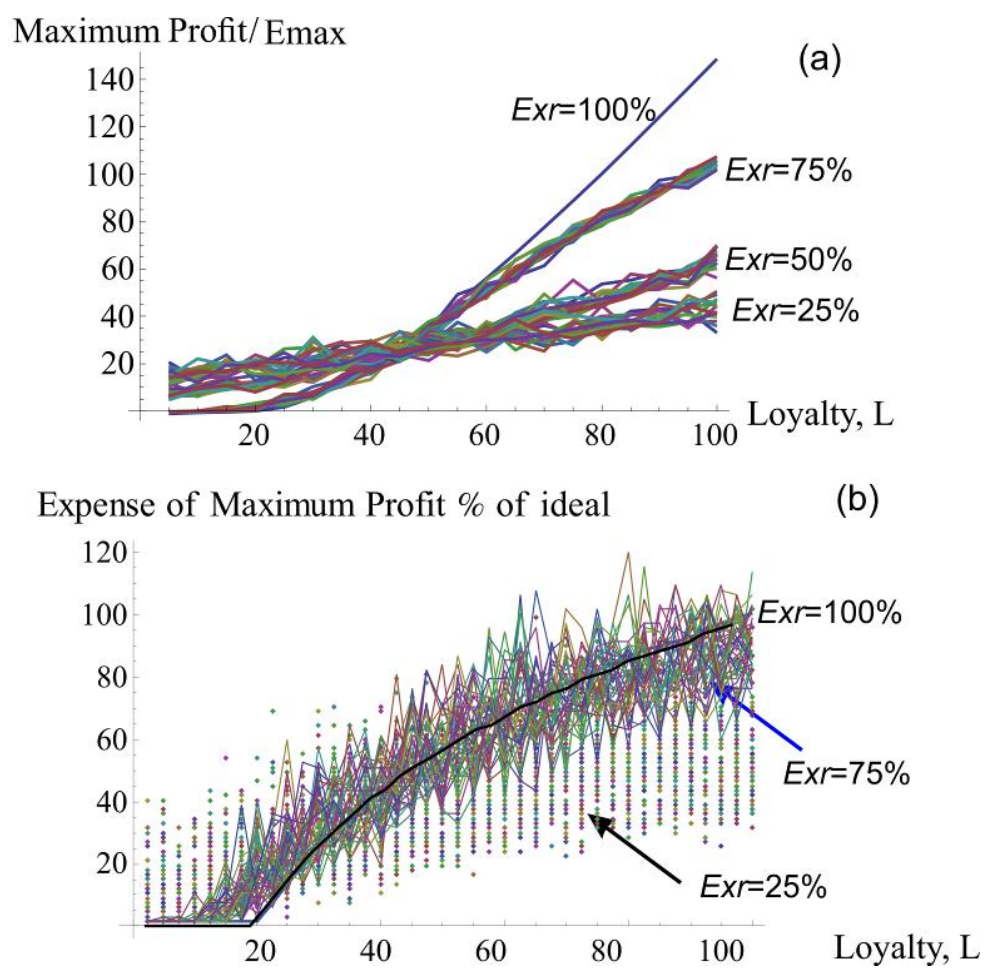

Figure 8. Conveyer-type business. (a) The maximum profit found from the profit-expense curves for loyalty ranging from $0-100 \%$ and $E x r$ taken at $(E x r=100 \%, 75,50,25 \%)$. Ideal maximum profit is $150 / \mathrm{E}_{\max }$. (b) The expense 
corresponding to the maximum profit found from the profit-expense curves for a range Loyalty $L$ of $0-100 \%$ and $E x r$ taken at $(E x r=100 \%, 75,25 \%)$. Ideal maximum profit is $150 / \mathrm{E}_{\max }$. The expense corresponding to the max profit is $100 / \mathrm{E}_{\max }$.

The analysis of the maximum profit and the expense corresponding to the maximum profit which can be obtained by the company for different $L$ and Exr are shown in Figure 8. From Figure 8a, one can see that the combined effect of non-100\% parameters $L$ and $E x r$ leads to a stronger profit decrease for the conveyer-type of business compared to retail. The effect of the decrease of expertise to $75 \%$ from $100 \%$ is close to none when loyalty is below $50 \%$. One can see that the effect of expertise is inversed (from decreasing to improving the company profit) at loyalty $L \sim 45-55 \%$ (compare to $L \sim 50-70 \%$ for retail).

Figure $8 \mathrm{~b}$ shows the results of the analysis of the expenses that correspond to the maximum profit for a conveyer-type of company. Similarly to the retail type, this expense depends on both loyalty (generally decreasing with the decrease of loyalty) and experience (decreasing (for $\mathrm{L}>20 \%$ ) and increasing (for $\mathrm{L}<30 \%$ ) with the decrease of experience). One can note that in virtually all cases, the expense of the maximum profit is always smaller than the expense corresponding to the ideal profit.

\subsubsection{Results for Model Based on both Assumptions 1 and 2}

We can now analyze the action of both Assumptions 1 and 2 together. As we demonstrated above, the action of careerism just moves profit along the profit-expense curve. Therefore, we did not include careerism explicitly in the analysis of the combined effect of both Assumptions 1 and 2. When using the model based on Assumption 2, we saw that the results were rather similar when using normal and uniform distributions of the managers' expenses. Therefore, to decrease the number of possible combinations, it makes sense to choose only one distribution to demonstrate the feature of the models suggested in this work. In this section we will use only normal distribution of the managers' expenses.

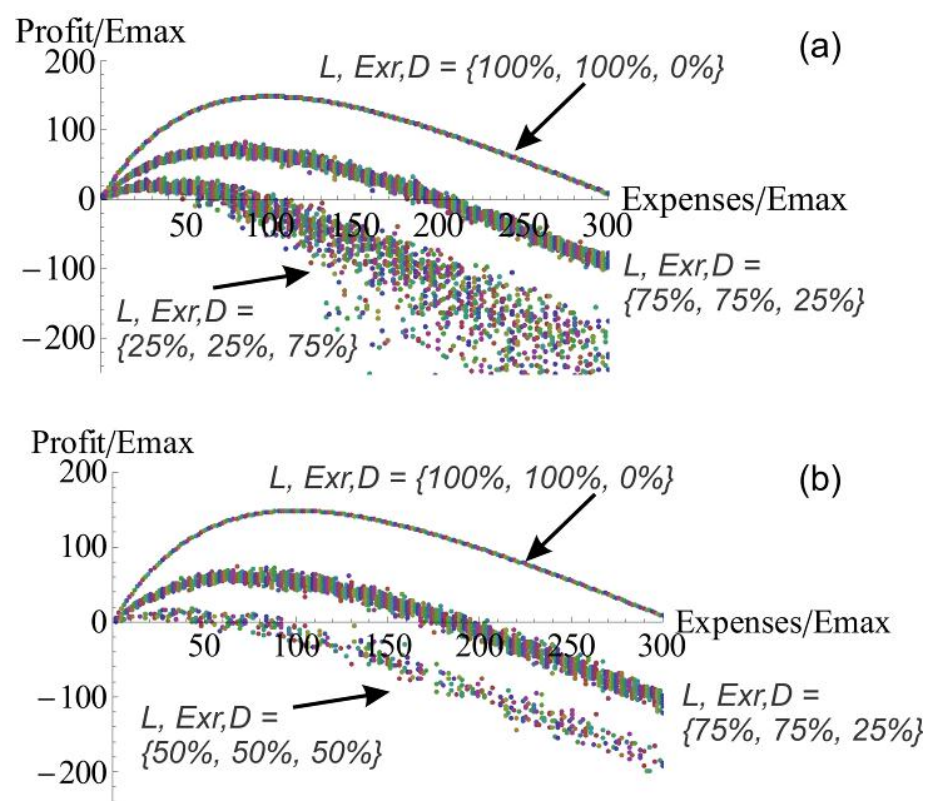

Figure 9. (a) Retail-type business. The profit-expense curves are shown for $L, E x r, D:\{100 \%, 100 \%, 0 \%\},\{75 \%, 75 \%$, $25 \%\},\{25 \%, 25 \%, 75 \%\}$. (b) Conveyer -type business. The profit-expense curves are shown for $L, E x r, D:\{100 \%$, $100 \%, 0 \%\},\{75 \%, 75 \%, 25 \%\},\{50 \%, 50 \%, 50 \%\}$.

Figure 9 demonstrates the effect of simultaneous changes of nanoeconomical parameters $L, E x r, D$ away from ideal. Figure 9a shows the effect of combined action of $L, E x r, D$ for (a) retail- and (b) conveyer-types of business. For simplicity and definiteness, combinations of $L=E x r=100 \%-D$ are considered. One can see that the additional increase of decentralization $D$ further decreases the company profit (compare with Figure $5 \mathrm{c}$ ). Figure $9 \mathrm{~b}$ shows a similar effect for the conveyer-type of business. One can qualitatively see the same additional profit-decreasing effect of decentralization $D$ (compare with Figure $7 \mathrm{~b}$ ). Comparing the conveyer- and retail-types of business, one can see that the cumulative action of nanoeconomical factors $L, E x r, D$ is stronger in the conveyer type case. While it is possible to gain $\sim 10 \%$ profit for retail business with $L, E x r, D=\{25 \%, 25 \%, 75 \%\}$, it is within single percents for conveyer business with only $L, E x r, D=\{50 \%, 50 \%, 50 \%\}$.

Figure 10 presents the results of a more detailed study of the effect of loyalty. Figure 10 a,c (for the retail- and 
conveyer- type of business, respectively) shows the maximum profit found from the profit-expense curves for loyalty ranging from $0-100 \%$ and specific values of $E x r, D$ (combinations of $E x r=100 \%-D$ are taken). When comparing with similar maximum profit curves calculated without decentralization $(D=0)$, Figs.6 and 8, one can see that decentralization further decreases the profit. However, the rate of the decrease is quite different, in particular, for the conveyer type of business. This rate is the largest when the profit is not too far from the ideal, and almost invisible for the low profit scenario (if it is so bad that it is impossible to make worse). For example, the maximum profit for the conveyer type of business is virtually zeroed when $D$ are taken at above $60 \%$ for Exr below $40 \%$.

It is interesting to note the following behavior which might be counterintuitive at first glance. In the case of large decentralization and low loyalty, the effect of low experience (parameter Exr) can result in the increase rather than decrease of the maximum profit. Moreover, the company maximum profit does not tend to zero even for zero loyalty. It brings a rather interesting conclusion: if the loyalty is low, a strong-hand policy (low decentralization) will not help, and lack of experience will even be advantageous. This counterintuitive result can be explained as follows. The managers could not harm the company profit effectively due to lack of knowledge/experience. Obviously, this is a rather unusual example of business when the loyalty, expertise, and decentralization are low. However, it is a good example demonstrating the difference between predictions of our model for retail and conveyer types of business. One can see from Figure 10 that the above scenario works only for the retail type of business (Figure 10a), and doesn't for the conveyer one (Figure 10c).

Figs.10 b,d (for the retail- and conveyer- type of business, respectively) demonstrate the effect of loyalty on the expense needed to gain maximum profit. Compared to Figs.6b and 8b, we now add a non-ideal (nonzero) decentralization. One can see that the effect of decentralization on the expense needed to gain maximum profit is very small. The effect of decentralization on both this expense and maximum profit are analyzed in more detail, and results are presented in Figure 11.

Figure 11 presents the results of the study similar to the shown in Figure 10 to demonstrate the detailed action of decentralization, $D$. We plot the maximum profit found from the profit-expense curves for a range of $D$ changing within $0-100 \%$ (taking multiple values of $L=E x r=100,75,50,10 \%$.). This is shown in Figure 11a,c for both retail- and conveyer- type of businesses. One can see that the retail- type of business can be quite stable with respect to the negative effects of decentralization. While it decreases the maximum profit of the company, it is not as bad as the decrease of loyalty and expertise. Moreover, if $L=E x r<50 \%$, decentralization virtually does not change the profit of such retail company. In the case of the conveyer-type of business, can be tolerated decentralization up to 40-50\%. However, above that limit, it leads to a substantial loss in the company profit.
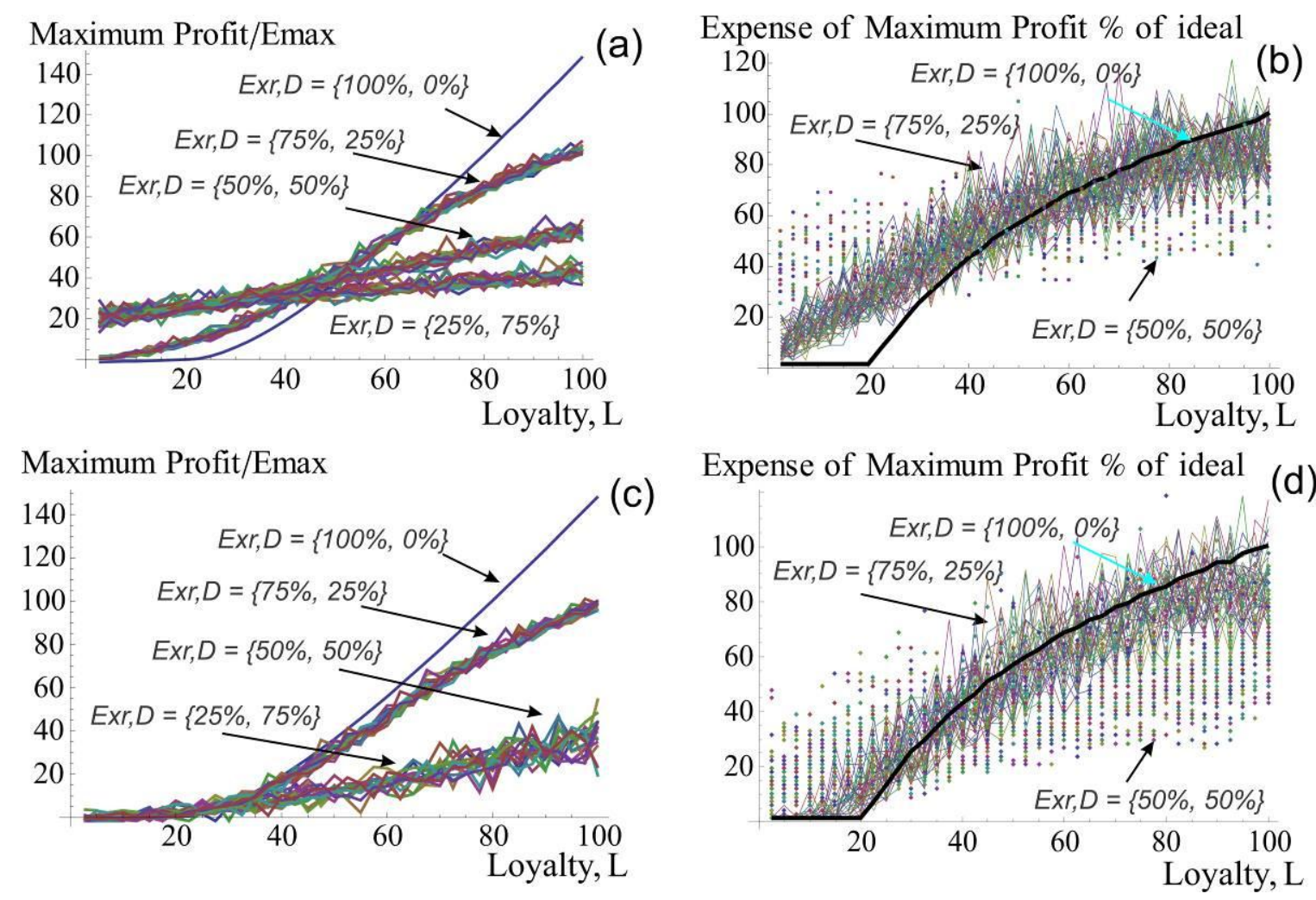

Figure 10. The maximum profit $(\mathrm{a}, \mathrm{c})$ and expense corresponding to the maximum profit $(\mathrm{b}, \mathrm{d})$ found form the 
profit-expense curves for loyalty ranging from $0-100 \%$ and $\operatorname{Exr}, D$ taken at: $\operatorname{Exr}, D=\{100 \%, 0 \%\},\{75 \%, 25 \%\},\{50 \%$, $50 \%\},\{25 \%, 75 \%\}$ for $(\mathrm{a}, \mathrm{c})$ and $\operatorname{Exr}, D=\{100 \%, 0 \%\},\{75 \%, 25 \%\},\{50 \%, 50 \%\}$ for $(\mathrm{b}, \mathrm{d})$. Two types of business are studied: (a,b) retail-, ( c,d) conveyer - type of business. Ideal maximum profit is $150 / \mathrm{E}_{\max }$. The expense corresponding to the max profit is $100 / \mathrm{E}_{\max }$.

Figure $11 \mathrm{~b}, \mathrm{~d}$ (for the retail- and conveyer- type of business, respectively) demonstrates the effect of decentralization on the expense that corresponds to the maximum profit. Due to a rather flat profit maximum, we obtain a large variation of the expense of the maximum profit. One can see that, in general, the effect of decentralization leads to a decrease of such expense, in particular, for the conveyer- type of business. Nevertheless, one can see that there is a relatively small percentage of the expenses that are greater than then expenses corresponding to the ideal maximum profit.

The other combinations of all four parameters introduced in our model are certainly possible. Due to the limited room, we stop here. We expect that the described quantitative model will allow researchers to continue exploring various combinations and to make further conclusions on the impact of nanoeconomics on the micro- and macro- economics.

Based of the above results, one can conclude that the nanoeconomical parameters introduced and analyzed in this work typically lead to the decrease of the company profit. The maximum profit of the company can almost always be attained with the expenses smaller than the expense corresponding to the maximum profit estimated without considering the nanoeconomical factors. The latter rule has an exception when decentralization, loyalty, and expertise are sufficiently high simultaneously. In such a situation, there is a small statistical percentage of cases in which the expense of maximum profit is larger than the one of ideal profit.

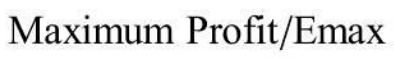

(a)

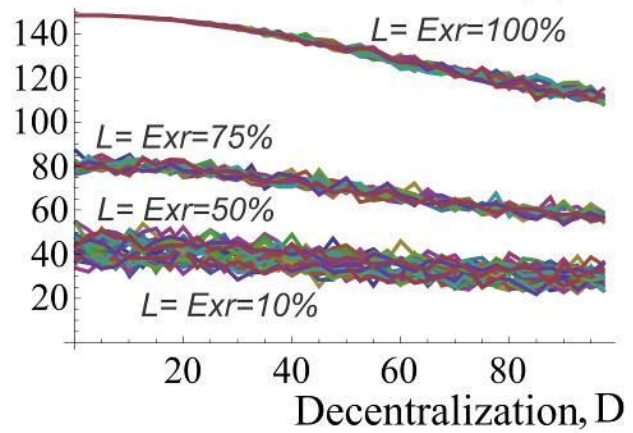

Maximum Profit/Emax

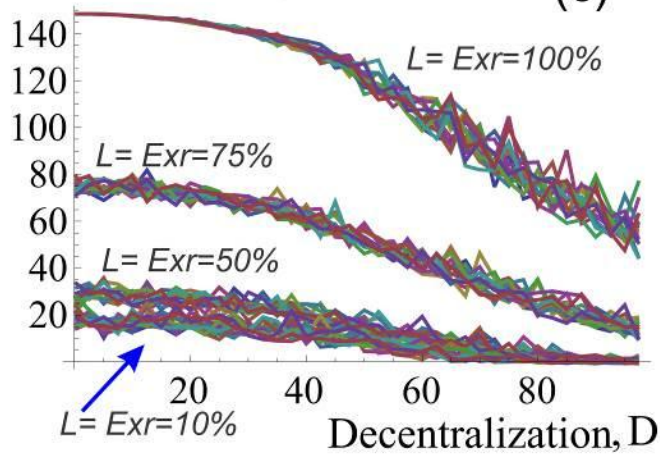

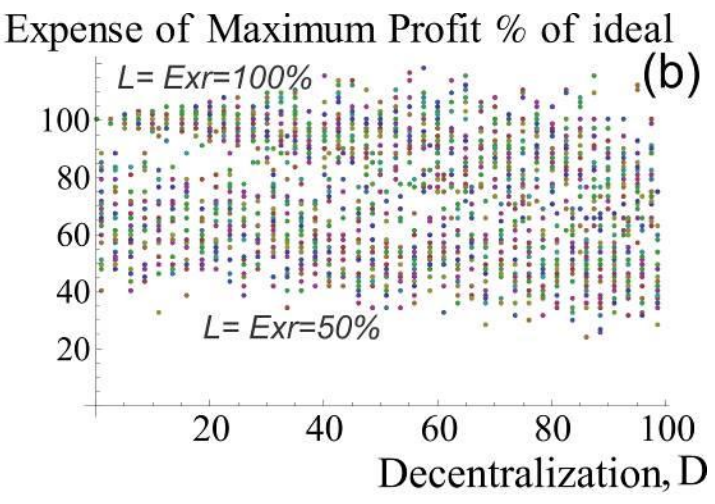

Expense of Maximum Profit \% of ideal

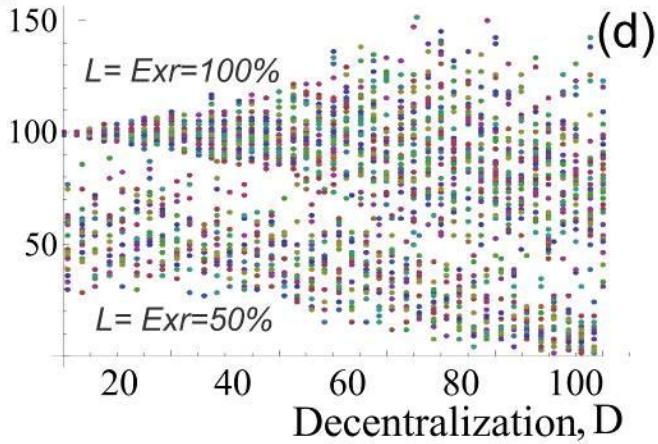

Figure 11. The Maximum Profit $(\mathrm{a}, \mathrm{c})$ and Expense Corresponding to the Maximum Profit $(\mathrm{b}, \mathrm{d})$ Found form the Profit-Expense Curves for a Range Decentralization $D$ of $0-100 \%$ taking Multiple,75,50,10\% for (a,c) and $L=$ $E x r=100,50 \%$ for $(\mathrm{b}, \mathrm{d})$.

Two types of business are studied: (a,b) retail-, (c,d) conveyer - type of business. Ideal maximum profit is $150 / \mathrm{E}_{\max }$. The expense corresponding to the max profit is $100 / \mathrm{E}_{\max }$.

\section{Conclusion}

Possible contradictions between the interests of the company and its decision makers is an important issue in the modern economy. These "nanoeconomical" factors are described in this work in a quantitative manner. Having a model describing such conflicts and their impact on the company profit can help to reduce the negative impacts and improve 
the efficiency of the company.

Specifically, here we described a view and model of modern economics, which takes into account the effect of possible contradiction between the interests of the company and its decision-makers. We assume that the company profit-related decisions are made as a result of multiple decisions of individual decision-makers (managers) who can follow their own interests rather the company ones. This is in contrast with the decision based exclusively the benefits of either company (ground of microeconomics) or society (ground of macroeconomics). Although these ideas have been discussed as early as in 1776 by Adam Smith, it seems to be particularly important now. Overall, the suggested model is in good agreement with the qualitative conclusion of the Agency Theory that the consideration of human factor leads to overestimated profit or an overvalued equity. In addition to that view of the Agency Theory, we formulated a quantitative statistical model in which each company profit-related decision is a contribution of decision made by a variety of individual decision-makers, managers. Within this model, we analyzed the change of the basic profit-expense curve, the contribution to this change from different human factors, or nanoeconomical parameters considered in the model, careerism and expertise of the managers, their loyalty to the company, and decentralization of company management.

The results of the present modeling can be summarized as follows. For almost all model cases, when taken the nanoeconomics factors into account, the company profit decreases with the increase of decentralization, and the decrease of expertise (of the managers) and loyalty (of managers to the company). The only exception of this effect is a hypothetical case of excessively low loyalty. In the latter case, the lack of managers' expertise improves the profit in the case of the retail type of business.

Careerism of managers, which pushes them to receive more expense funds, just moves profit along the profit-expense curve. If the company operates close to the possible maximum of profit, the further increase of expense should lead to the decrease of profit. Interestingly, our model shows that the effect of careerism can, in principle, be removed by renormalizing/decreasing all manager expenses by a factor to keep the total company expense unchanged.

Next, the developed model suggests that the effect of decentralization can be well-tolerated in the retail- type of business. While it slightly decreases the maximum profit of the company, it is not as bad as the decrease of loyalty and expertise. Moreover, if loyalty and expertise drop below 50\%, decentralization virtually does not change profit of the retail company. In the case of conveyer-type of business, decentralization can be tolerated only up to 40-50\%, and it leads to a substantial decrease of the company profit above that limit.

Finally, we found that the maximum profit of the company, which decreases after taking into account the nanoeconomical factors, can almost always be attained with the expenses smaller than the expense corresponding to the ideal maximum profit (profit estimated without considering the nanoeconomical factors). There is a small statistical percentage of cases in which the expense of maximum profit is larger than the one of ideal profit exception when decentralization, loyalty, and expertise are sufficiently high simultaneously. If we ignore this statistically small number of cases, this conclusion may lead to an interesting conclusion: if a company is losing profit due to nanoeconomical factors, to reach the maximum profit, one needs to decrease the expenses compared to the microeconomics estimations. This strategy is indeed used by a number of managers.

In conclusion, it is worth of noting that the presented model and view on nanoeconomical issues of modern economy is just a first attempt to introduce a rigorous quantitative description of possible contradictions between the interests of the company and its decision makers. More work has to be done to find implications of the described approach for each particular company. Being plausible, the nanoeconomical parameters (careerism and expertise of the managers, their loyalty to the company, and decentralization of company management) were introduced in the model ad hoc. Because the meaning of these parameters is defined, it creates a way to evaluate the parameters with the help of special tests, questionnaires, and analysis of the company performance. It will be done in future works.

\section{References}

Alchian, A. A. (1965). The Economics of Discretionary Behavior - Managerial Objectives in a Theory of the Firm Williamson, De. Econometrica, 33(4), 881-882. http://dx.doi.org/10.2307/1910367

Alchian, A. A., \& Demsetz, H. (1972). Production, Information Costs, and Economic Organization. American Economic Review, 62(5), 777-795.

Brock, W. A., \& Durlauf, S. N. (2001). Discrete choice with social interactions. Review of Economic Studies, 68(2), 235-260. http://dx.doi.org/10.1111/1467-937x.00168

Dawson, L. (2009). Stockholders Versus Stakeholders: Implications for Business Ethics. Philosophy of Management, 7 , $3-12$. 
Eisenhardt, K. M. (1985). Control - Organizational and Economic Approaches. Management Science, 31(2), 134-149. http://dx.doi.org/10.1287/mnsc.31.2.134

Eisenhardt, K. M. (1989). Agency Theory - an Assessment and Review. Academy of Management Review, 14(1), 57-74. http://dx.doi.org/10.2307/258191

Hargreaves, D. H. (1996). Diversity and choice in school education: A modified libertarian approach. Oxford Review of Education, 22(2), 131-141. http://dx.doi.org/10.1080/0305498960220201

Jensen, M. C. (2005). Agency costs of overvalued equity. Financial Management, 34(1), 5-19. http://dx.doi.org/10.1111/j.1755-053X.2005.tb00090.x

Jensen, M. C., \& Meckling, W. H. (1976). Theory of Firm - Managerial Behavior, Agency Costs and Ownership Structure. Journal of Financial Economics, 3(4), 305-360. http://dx.doi.org/10.1016/0304-405x(76)90026-X

Karnani, A. (2010). Failure of the libertarian approach to reducing poverty. Asian Business \& Management, 9(1), 5-21. http://dx.doi.org/10.1057/Abm.2009.20

Kuratko, D. F., \& Goldsby, M. G. (2004). Corporate entrepreneurs or rogue middle managers? A framework for ethical corporate entrepreneurship. Journal of Business Ethics, 55(1), 13-30.

Oconnell, J. (1965). The Economics of Discretionary Behavior - Managerial Objectives in a Theory of the Firm Williamson,Oe. Economica, 32(128), 473-474. http://dx.doi.org/10.2307/2552785

Ostgaard, T. A., \& Birley, S. (1994). Personal Networks and Firm Competitive Strategy - a Strategic or Coincidental Match. Journal of Business Venturing, 9(4), 281-305. http://dx.doi.org/10.1016/0883-9026(94)90009-4

Ramdani, D., \& van Witteloostuijn, A. (2012). The Shareholder-Manager Relationship and Its Impact on the Likelihood of Firm Bribery. Journal of Business Ethics, 108(4), 495-507. http://dx.doi.org/10.1007/s10551-011-1105-5

Riasi, A., \& Asadzadeh, N. (2015). The relationship between principals' reward power and their conflict management styles based on Thomas-Kilmann conflict mode instrument. Management Science Letters, 5(6), 611-618.

Sen, P. K. (2007). Ownership incentives and management fraud. Journal of Business Finance \& Accounting, 34(7-8), 1123-1140. http://dx.doi.org/10.1111/j.1468-5957.2007.02026.x

Smith, A., \& Marian S. Carson Collection (Library of Congress). (1796). An inquiry into the nature and causes of the wealth of nations (A new edition. ed.). Philadelphia: Printed by Thomas Dobson.

Sornette, D. (2014). Physics and financial economics (1776-2014): puzzles, Ising and agent-based models. Reports on Progress in Physics, 77(6). http://dx.doi.org/10.1088/0034-4885/77/6/062001

Zannetos, Z. S. (1965). The Economics of Discretionary Behavior - Managerial Objectives in a Theory of the Firm Williamson,Oe. Journal of Business, 38(4), 421-424. http://dx.doi.org/10.1086/294809

Zhang, X. B., Zhang, Z. G., \& Chen, Z. L. (2007). A principal-agent problem. Proceedings of 2007 Ieee International Conference on Grey Systems and Intelligent Services, 1(2), 1293-1296.

\section{Copyrights}

Copyright for this article is retained by the author(s), with first publication rights granted to the journal.

This is an open-access article distributed under the terms and conditions of the Creative Commons Attribution license which permits unrestricted use, distribution, and reproduction in any medium, provided the original work is properly cited. 